\title{
THE ARTERIAL PRESSURE PULSE IN MUSCULAR SUBAORTIC STENOSIS
}

\author{
BY \\ E. DOUGLAS WIGLE* \\ From the Department of Medicine, University of Toronto, and the Cardiovascular Unit, \\ Toronto General Hospital, Toronto, Canada
}

Received March 5, 1962

Brock $(1957,1959)$ using the term "Functional obstruction of the left ventricle" was the first to describe muscular subaortic stenosis. Since then, a number of reports (Bercu et al., 1958; Morrow and Braunwald, 1959; Brent et al., 1960; Goodwin et al., 1960; Braunwald et al., 1960; Brachfeld and Gorlin, 1959, 1961 ; Paré et al., 1961; Boiteau and Allenstein, 1961) have appeared concerning this condition, the majority of which have noted the characteristic arterial pulse contour described by Brachfeld and Gorlin (1959). The latter authors (1959) and Goodwin et al. (1960) drew attention to the fast rising, early peaked arterial pulse pressure in muscular subaortic stenosis, which contrasted with the anacrotic slow rising pulse seen in valvular aortic stenosis. There appeared, however, to be a conflict of opinion concerning the arterial pulse contour in discrete, fixed subaortic stenosis. Thus, Brachfeld and Gorlin (1959) stated "a tight fibrous subaortic ring unassociated with muscular hypertrophy could theoretically be associated with an anacrotic shoulder. The relative rarity of such a lesion, however, makes the presence of marked anacrotism probably incompatible with a diagnosis of subaortic stenosis." Hancock (1961), on the other hand, described an anacrotic pulse in a case of membranous subaortic stenosis proven at operation and contrasted this pulse contour with that seen in muscular and fibromuscular subaortic stenosis, where the pulse contour was fast rising with an early peak systolic pressure. Kjellberg et al. (1959) and Brock and Fleming (1956) have also reported an anacrotic pulse in discrete subaortic stenosis.

Because there was this difference of opinion and because of the importance in differentiating the muscular from the discrete fixed varieties of aortic stenosis, a detailed comparison was made of the arterial pulse contour in these groups. It is the purpose of this report to show that there were distinctive differences in the arterial pulse contour in muscular subaortic stenosis when compared with either valvular or discrete subvalvular aortic stenosis.

\section{SubJeCtS AND Methods}

The ten cases of muscular subaortic stenosis have been reported elsewhere (Wigle, Heimbecker, and Gunton, 1962). Brachial arterial pressure tracings were available in all these cases and withdrawal pressure tracings across the left ventricular outflow tract in five. Brachial arterial pressure tracings were available in 6 of 8 surgically proven cases of discrete subaortic stenosis and withdrawal pressure tracings across the left ventricular outflow tract in 5, including the two cases that did not have brachial arterial pressure tracings. The brachial arterial pressure pulse was also analysed in 20 cases of aortic valvular stenosis for comparison with the two groups of subvalvular aortic stenosis. In 2 of these, withdrawal tracings across the left ventricular outflow tract were recorded. The brachial arterial pressure tracings of 10 hæmodynamically normal subjects were also studied.

The following parameters of the arterial pressure pulse were analysed: (1) rate of rise of pressure in $\mathrm{mm}$. $\mathrm{Hg} / \mathrm{sec}$. from the onset of the pressure rise to the anacrotic notch or percussion wave; (2) the time from

* Supported by the Ontario Heart Foundation. 
TABLE

Hamodynamics of Brachial Arterial Pressure Pulse in Valvular and Various forms of Subvalvular Aortic Stenosis

\begin{tabular}{|c|c|c|c|c|c|c|c|c|c|c|}
\hline & & & & \multirow[b]{2}{*}{ Case No. } & \multirow[b]{2}{*}{ Gradient } & \multirow[b]{2}{*}{$\begin{array}{l}\text { Rate of rise } \\
\text { of pressure }\end{array}$} & \multicolumn{4}{|c|}{$\begin{array}{c}\text { Time in seconds from beginning of } \\
\text { upstroke to: }\end{array}$} \\
\hline & & & & & & & $\begin{array}{l}\text { Percussion } \\
\text { wave }\end{array}$ & $\begin{array}{l}\text { Maximal } \\
\text { pressure }\end{array}$ & $\begin{array}{l}\text { Tidal } \\
\text { wave }\end{array}$ & $\begin{array}{c}\text { Dicrotic } \\
\text { notch }\end{array}$ \\
\hline Normal & $\cdots \quad \cdots$ & . & $\cdots$ & $\begin{array}{r}1 \\
2 \\
3 \\
4 \\
5 \\
6 \\
7 \\
8 \\
9 \\
10\end{array}$ & $\begin{array}{l}0 \\
0 \\
0 \\
0 \\
0 \\
0 \\
0 \\
0 \\
0 \\
0\end{array}$ & $\begin{array}{r}1440 \\
550 \\
960 \\
455 \\
550 \\
685 \\
1150 \\
810 \\
490 \\
885\end{array}$ & $\begin{array}{l}0.04 \\
0.09 \\
0.11 \\
0.13 \\
0.11 \\
\\
0.04 \\
0.10 \\
\\
0.09\end{array}$ & $\begin{array}{l}0 \cdot 10 \\
0.21 \\
0.24 \\
0.21 \\
0 \cdot 17 \\
0 \cdot 16 \\
0 \cdot 12 \\
0 \cdot 10 \\
0 \cdot 21 \\
0.09\end{array}$ & $\begin{array}{l}0.19 \\
0.21 \\
0.24 \\
0.21 \\
0.36 \\
\\
0.20 \\
0.26 \\
\\
0.22\end{array}$ & $\begin{array}{l}0.28 \\
0.28 \\
0.36 \\
0.36 \\
0.37 \\
0.39 \\
0.30 \\
0.32 \\
0.43 \\
0.31\end{array}$ \\
\hline \multicolumn{4}{|c|}{ Muscular subaortic stenosis } & $\begin{array}{r}1 \\
2 \\
3 \\
4 \\
5 \\
6 \\
7 \\
8 \\
9 \\
10\end{array}$ & $\begin{array}{r}45 \\
67 \\
20 \\
56 \\
40 \\
25 \\
30 \\
75 \\
113 \\
85\end{array}$ & $\begin{array}{r}1010 \\
650 \\
1340 \\
635 \\
1040 \\
1980 \\
1300 \\
1135 \\
1300 \\
1700\end{array}$ & $\begin{array}{l}0.08 \\
0.07 \\
0.08 \\
0.09 \\
0.05 \\
0.05 \\
0.07 \\
0.05 \\
0.05 \\
0.07\end{array}$ & $\begin{array}{l}0.08 \\
0.07 \\
0.08 \\
0.09 \\
0.05 \\
0.05 \\
0.07 \\
0.05 \\
0.05 \\
0.07\end{array}$ & $\begin{array}{l}0.24 \\
0.29 \\
0.22 \\
0.28 \\
0.28 \\
0.23 \\
0.30 \\
0.33 \\
0.24 \\
0.34\end{array}$ & $\begin{array}{l}0.40 \\
0.40 \\
0.34 \\
0.42 \\
0.38 \\
0.30 \\
0.37 \\
0.41 \\
0.44 \\
0.43\end{array}$ \\
\hline \multicolumn{4}{|c|}{ Discrete subaortic stenosis } & $\begin{array}{l}1 \\
2 \\
3 \\
4 \\
5 \\
6\end{array}$ & $\begin{array}{r}50 \\
60 \\
60 \\
100 \\
105 \\
120\end{array}$ & $\begin{array}{l}425 \\
590 \\
300 \\
180 \\
375 \\
300\end{array}$ & $\begin{array}{l}0 \cdot 14 \\
0 \cdot 14 \\
0 \cdot 16 \\
0 \cdot 12 \\
0.09\end{array}$ & $\begin{array}{l}0.22 \\
0.17 \\
0.31 \\
0.24 \\
0.25 \\
0.21\end{array}$ & $\begin{array}{l}0.22 \\
0.22 \\
0.31 \\
0.24 \\
0.25 \\
0.21\end{array}$ & $\begin{array}{l}0.33 \\
0.29 \\
0.41 \\
0.42 \\
0.38\end{array}$ \\
\hline \multirow{4}{*}{ 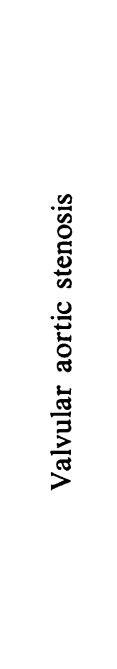 } & Mild .. & $\cdots$ & $\cdots$ & $\begin{array}{l}1 \\
2 \\
3 \\
4\end{array}$ & $\begin{array}{l}24 \\
25 \\
41 \\
50\end{array}$ & $\begin{array}{l}400 \\
400 \\
480 \\
430\end{array}$ & $\begin{array}{l}0.04 \\
0.10 \\
0.09 \\
0.08\end{array}$ & $\begin{array}{l}0 \cdot 23 \\
0 \cdot 25 \\
0 \cdot 23 \\
0 \cdot 21\end{array}$ & $\begin{array}{l}0.23 \\
0.25 \\
0 \cdot 23 \\
0 \cdot 21\end{array}$ & $\begin{array}{l}0 \cdot 32 \\
0 \cdot 37 \\
0 \cdot 37 \\
0 \cdot 39\end{array}$ \\
\hline & Moderate & $\cdots$ & . & $\begin{array}{l}5 \\
6 \\
7\end{array}$ & $\begin{array}{l}55 \\
60 \\
65\end{array}$ & $\begin{array}{l}305 \\
405 \\
355\end{array}$ & $\begin{array}{l}0.09 \\
0.08\end{array}$ & $\begin{array}{l}0.26 \\
0.27 \\
0.26\end{array}$ & $\begin{array}{l}0.26 \\
0.27 \\
0.26\end{array}$ & $\begin{array}{l}0.44 \\
0.37 \\
0.37\end{array}$ \\
\hline & Severe & . & . & $\begin{array}{r}8 \\
9 \\
10 \\
11 \\
12 \\
13\end{array}$ & $\begin{array}{l}100 \\
102 \\
135 \\
140 \\
140 \\
165\end{array}$ & $\begin{array}{l}235 \\
190 \\
255 \\
225 \\
245 \\
345\end{array}$ & $\begin{array}{l}0.12 \\
0.15 \\
0.12 \\
0.10 \\
0.06\end{array}$ & $\begin{array}{l}0.29 \\
0.31 \\
0.26 \\
0.26 \\
0.27 \\
0.19\end{array}$ & $\begin{array}{l}0.29 \\
0.31 \\
0.26 \\
0.26 \\
0.27 \\
0.19\end{array}$ & $\begin{array}{l}0.43 \\
0.46 \\
0.38 \\
0.43 \\
0.39 \\
0.34\end{array}$ \\
\hline & $\begin{array}{l}\text { Severe }+\mathrm{mi} \\
\text { aortic } \\
\text { regurgita }\end{array}$ & $\begin{array}{l}\text { ld } \\
\text { tion }\end{array}$ & $\cdots$ & $\begin{array}{l}14 \\
15 \\
16 \\
17 \\
18 \\
19 \\
20\end{array}$ & $\begin{array}{r}40 \\
80 \\
88 \\
100 \\
100 \\
105 \\
160\end{array}$ & $\begin{array}{l}385 \\
340 \\
320 \\
455 \\
935 \\
750 \\
405\end{array}$ & $\begin{array}{l}0.09 \\
0.12 \\
0.11 \\
0.06 \\
0.03 \\
0.06 \\
0.10\end{array}$ & $\begin{array}{l}0.27 \\
0.31 \\
0.30 \\
0.26 \\
0.25 \\
0.28 \\
0.26\end{array}$ & $\begin{array}{l}0.27 \\
0.31 \\
0.30 \\
0.26 \\
0.25 \\
0.28 \\
0.26\end{array}$ & $\begin{array}{l}0.37 \\
0.43 \\
0.47 \\
0.34 \\
0.44 \\
0.38 \\
0.40\end{array}$ \\
\hline
\end{tabular}

All figures except the rate of rise of pressure are corrected for heart rate by dividing by the square root of the cycle length (Wood, 1958). 
the onset of rise of pressure to $(a)$ the percussion wave (or anacrotic notch), $(b)$ the point of maximal pressure, $(c)$ the tidal wave, and $(d)$ the dicrotic notch. Each of these times was corrected for heart rate by dividing by the square root of the cycle length (Wood, 1958).

The brachial arterial pressure tracings were recorded through indwelling catheters (polyethylene 160) or No. 20 gauge arterial needles on either a photographic recorder* using a strain gauge $\dagger$ or a direct writing recorder $\ddagger$ using a capacitance manometer $\S$. Withdrawal pressure tracings across the left ventricular outflow tract were obtained at the time of left heart catheterization either by the transthoracic method (Björk, Malmström, and Uggla, 1953), or by retrograde left ventricular catheterization.

\section{RESULTS}

Detailed analysis of the brachial arterial pressure tracings in the 10 normal cases, 10 cases of muscular subaortic stenosis, 6 of 8 cases of discrete subaortic stenosis, and 20 cases of valvular aortic stenosis are given in the Table. The length of time from the onset of the pressure rise to the percussion wave, tidal wave, and dicrotic notch was not helpful in differentiating the normal subjects from cases of aortic stenosis or in differentiating between the types of aortic stenosis. The most notable differential features, the systolic upstroke time to the peak systolic pressure and the rate of rise of pressure, are plotted graphically in Fig. 2 and 3. There was a clear distinction of muscular subaortic stenosis from valvular and discrete subvalvular aortic stenosis using the systolic upstroke time to the maximal systolic pressure. Although the average values for the rate of rise of pressure in muscular and discrete fixed varieties of aortic stenosis were also quite different, there was overlap preventing clear distinction. Inspection of the tracings was usually sufficient to decide whether the stenosis was of a fixed or muscular variety (Fig. 5, 6, 7, and 8). In the muscular variety there was a rapid rise of pressure to a high percussion wave (the peak systolic pressure) followed by a dwarfed late tidal wave followed by the dicrotic wave (Fig. 1 and 7). In either valvular or discrete subvalvular aortic stenosis there was a slow rate of rise of pressure to a low percussion wave (anacrotic notch) followed by a higher tidal wave (the peak systolic pressure), then the dicrotic notch (Fig. 5 and 8).

Analysis was also made of the withdrawal pressure tracings across the left ventricular outflow tract in five cases of muscular subaortic stenosis, and the aortic pressure tracings were identical in shape with the brachial arterial tracings. The outflow tract of the left ventricle

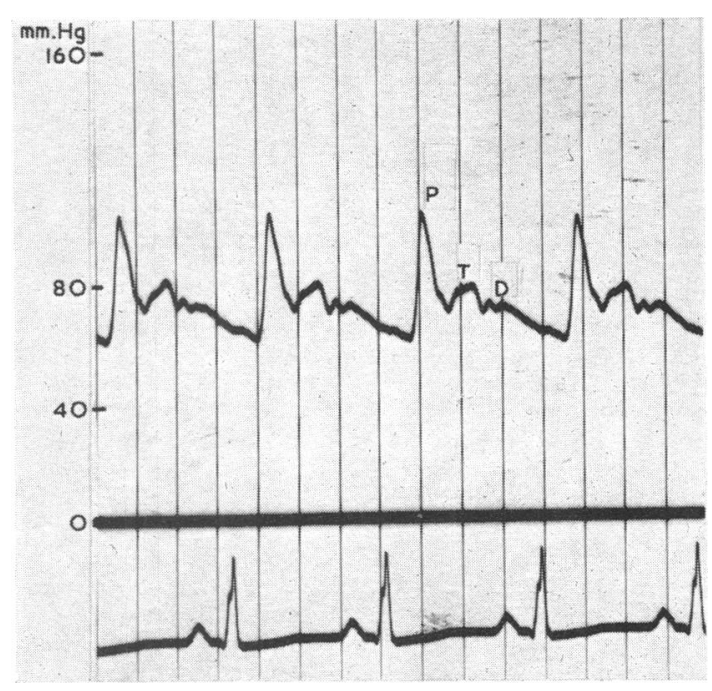

Fig. 1.-Left brachial arterial pressure tracing from a case of surgically proven muscular subaortic stenosis. Note the rapid rate of rise of pressure from the onset to the high percussion peak $(P)$ and the late dwarfed tidal wave (T). The maximal pressure (P) occurs early in systole and results in a short systolic upstroke time to the maximal systolic pressure. $\mathrm{D}$ is the dicrotic wave. above the muscular narrowing also had the characteristic rapid rise of pressure to the high percussion wave (peak systolic pressure) and a dwarfed delayed tidal wave (Fig. 9). In the aortic and withdrawal pressure tracings in five cases of discrete subaortic stenosis, the characteristics of the pressure pulse were also similar to those seen in the peripheral arterial pulse in these cases (slow rate of rise of pressure and prolonged systolic upstroke time) (Fig. 10). There were times, however, when the aortic pressure tracing resembled that seen in muscular subaortic stenosis, i.e. rapid rate of rise of pressure and

*Electronics for Medicine, White Plains, New York. $\dagger$ P23Db-Statham Instruments Inc. of Puerto Rico. $\ddagger$ Twin-Viso Recorder Sanborn Co., Cambridge, Mass. $\S$ Sanborn Co., Cambridge, Mass. 


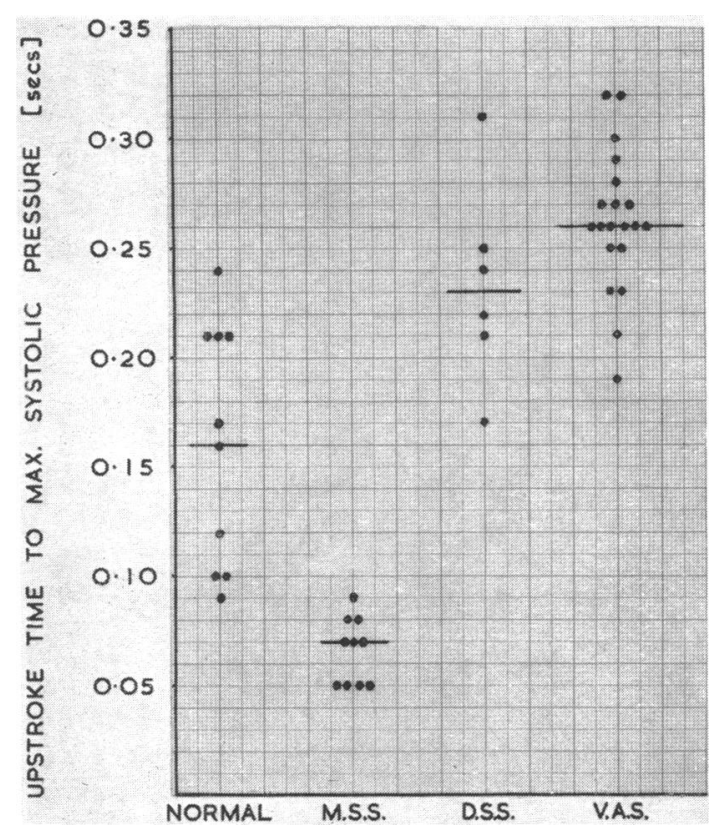

FIG. 2.-The upstroke time from the onset of the pressure rise to the maximal systolic pressure in the brachial arterial pressure trace in 10 normal subjects, 10 patients with muscular subaortic stenosis (M.S.S.), 6 patients with discrete subaortic stenosis (D.S.S.), and 20 patients with valvular aortic stenosis (V.A.S.). The horizontal lines represent the average upstroke time in each group. There is a short upstroke time in muscular subaortic stenosis and a prolonged upstroke time in fixed subvalvular and valvular aortic stenosis.

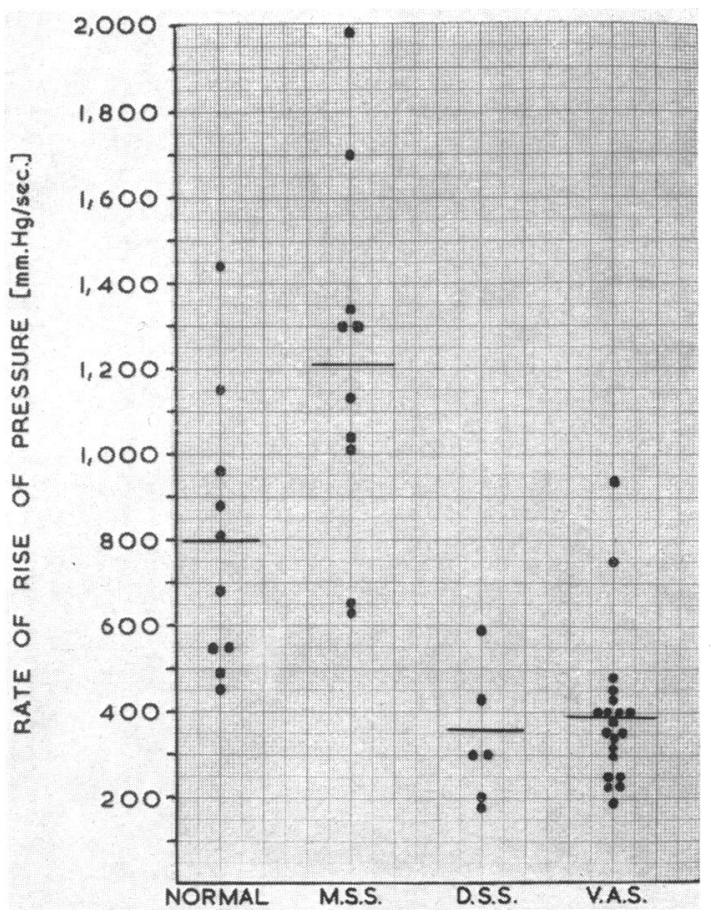

FIG. 3. The rate of rise of pressure $(\mathrm{mm}$. $\mathrm{Hg} / \mathrm{sec}$. $)$ from the onset of the pressure rise to the anacrotic notch or percussion wave in the brachial arterial pressure tracing in 10 normal subjects, 10 patients with muscular subaortic stenosis (M.S.S.), 6 patients with discrete subaortic stenosis (D.S.S.), and 20 patients with valvular aortic stenosis (V.A.S.). The horizontal lines represent the average for each group. There is overlap in the rate of rise of pressure in two cases with V.A.S., whose rates of rise were 750 and $935 \mathrm{~mm} . \mathrm{Hg} / \mathrm{sec}$. The arterial pressure trace in the latter case is shown in Fig. 4 and the systolic upstroke time is prolonged, allowing differentiation from muscular subaortic stenosis.

early peak systolic pressure (Fig. 11). Such rapid rates of rise of pressure in the aortic pressure pulses in discrete subaortic stenosis occurred only when the catheter was at or near the valve level and were not encountered when the catheter was distant from the aortic valve area. Similar rapid rates of rise in the aortic pressure tracings were intermittently seen in proven valvular aortic stenosis when the catheter was at the valve level, yet the peripheral arterial tracing in such cases (as well as the majority of the aortic tracing) showed the slow rate of rise and the peak systolic pressure (tidal wave) occurring late. Because of these variations, the aortic pressure pulses were not as reliable as brachial arterial tracings in the differentiation of muscular from the fixed types of aortic stenosis.

Brockenbrough, Braunwald, and Morrow (1961) reported a decreased arterial pulse pressure in muscular subaortic stenosis in the beat following a long diastolic pause after a premature beat. In cases of discrete aortic stenosis (valvular and subvalvular) these authors found that the arterial pulse pressure was greater after a long diastolic pause. In the present study these observations have been confirmed. 


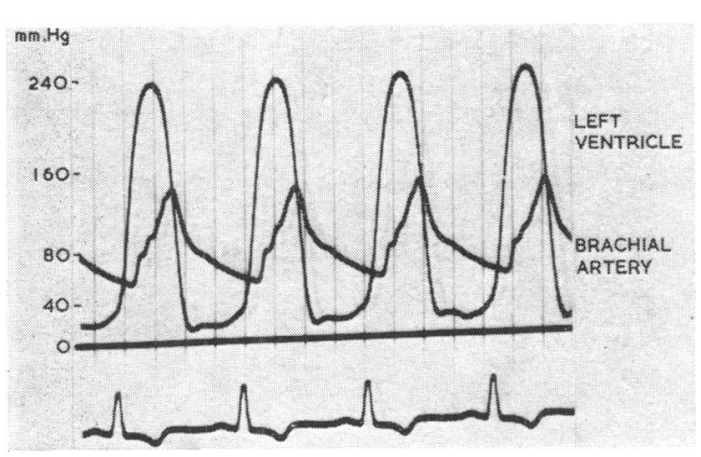

Fig. 4.-Simultaneous left ventricular and brachial arterial pressure traces in a case of severe valvular aortic stenosis showing an unusually rapid rate of rise of pressure from the onset of the pressure rise to the anacrotic notch (percussion wave). However, the tidal wave represents the maximum systolic pressure, thus the systolic upstroke time is prolonged allowing the differentiation from muscular subaortic stenosis (Fig. 2).

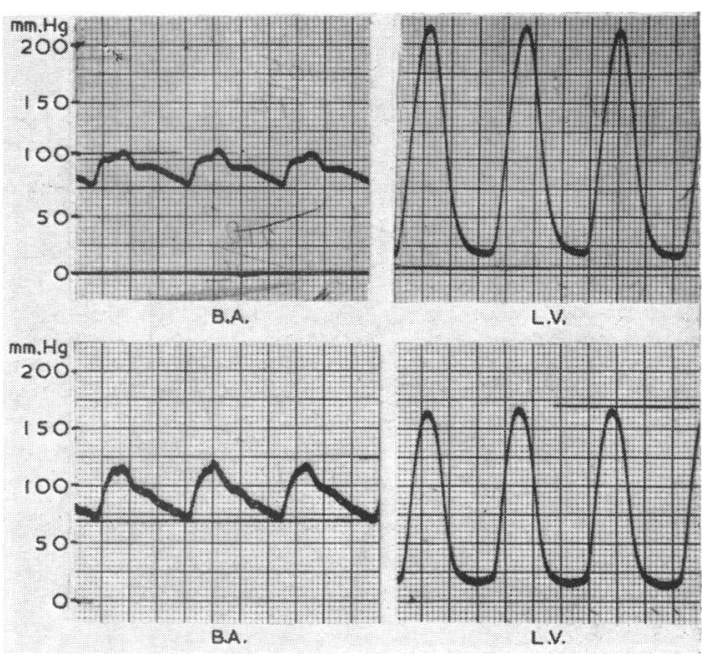

Fig. 5.-Simultaneous low left ventricular (L.V.) and brachial (B.A.) pressure traces in two cases of discrete fixed subaortic stenosis (see text).

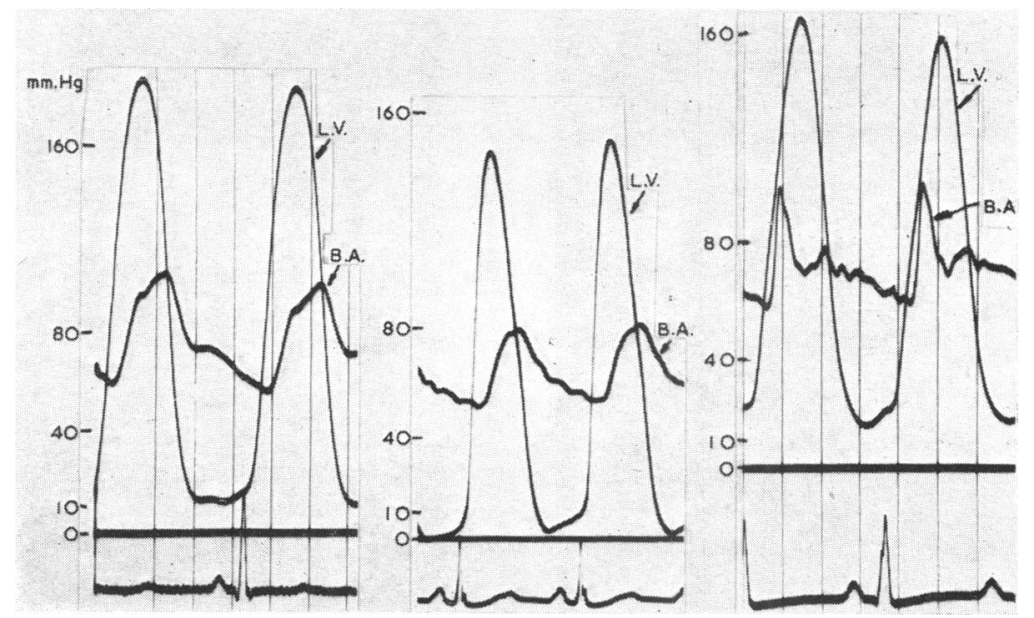

Fig. 6.-Simultaneous low left ventricular (L.V.) and brachial arterial (B.A.) pressure traces in cases of aortic valvular stenosis (left), discrete subaortic stenosis (centre), and muscular subaortic stenosis (right). The rate of rise of pressure in the brachial artery is slow in the fixed stenoses (left and centre) and rapid in muscular subaortic stenosis. The pressure rise in the brachial artery in the latter parallels the pressure rise in the left ventricle, whereas in the fixed stenoses the pressure rise in the brachial artery is slower than that in the ventricle. The systolic upstroke time to the peak systolic pressure in B.A. trace is short in the muscular variety because the peak pressure is the percussion wave whereas in the fixed stenoses the upstroke time is prolonged because the peak pressure is the tidal wave. Inspection of the brachial arterial pressure traces suffices to differentiate the muscular from the fixed stenoses. 


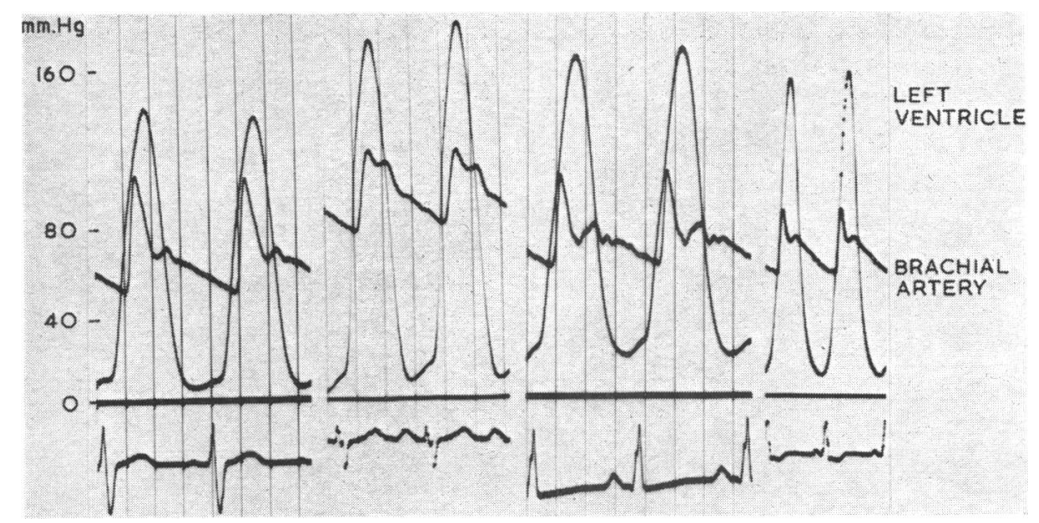

FIG. 7.- Simultaneous low left ventricular and brachial arterial pressure traces in four cases of muscular subaortic stenosis (see text). Contrast these arterial traces with those in Fig. 8.
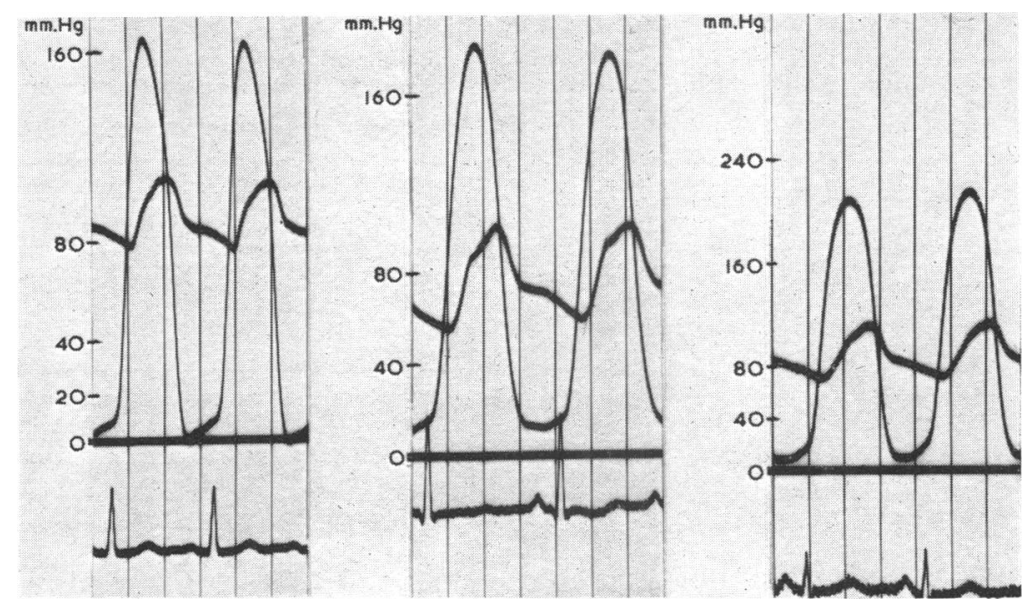

FIG. 8.-Simultaneous left ventricular and brachial arterial pressure traces in mild (left), moderate (centre), and severe (right) valvular aortic stenosis. Contrast with Fig. 7.

\section{Discussion}

From the above results it was concluded that there were significant differences in the shape of the arterial pressure tracing between muscular subaortic stenosis and valvular and discrete subvalvular aortic stenosis. In muscular subaortic stenosis the rate of rise of pressure was rapid to the peak systolic pressure (percussion wave) giving a short systolic upstroke time to the peak systolic pressure. In valvular and discrete subvalvular aortic stenosis the rate of rise of pressure was slow and the peak systolic pressure (tidal wave) was late, giving a prolonged systolic upstroke time to the peak systolic pressure. These differences were evident in both the peripheral arterial pressure tracing and in the aortic pressure tracings, but in the latter, alterations in the tracings occurred when the catheter was near the aortic valve, making analysis of the shape of the tracings difficult. In addition, withdrawal pressure tracings across the left ventricular outflow tract were not infallible. In aortic valvular stenosis evidence of an infundibular chamber was obtained when none existed, 


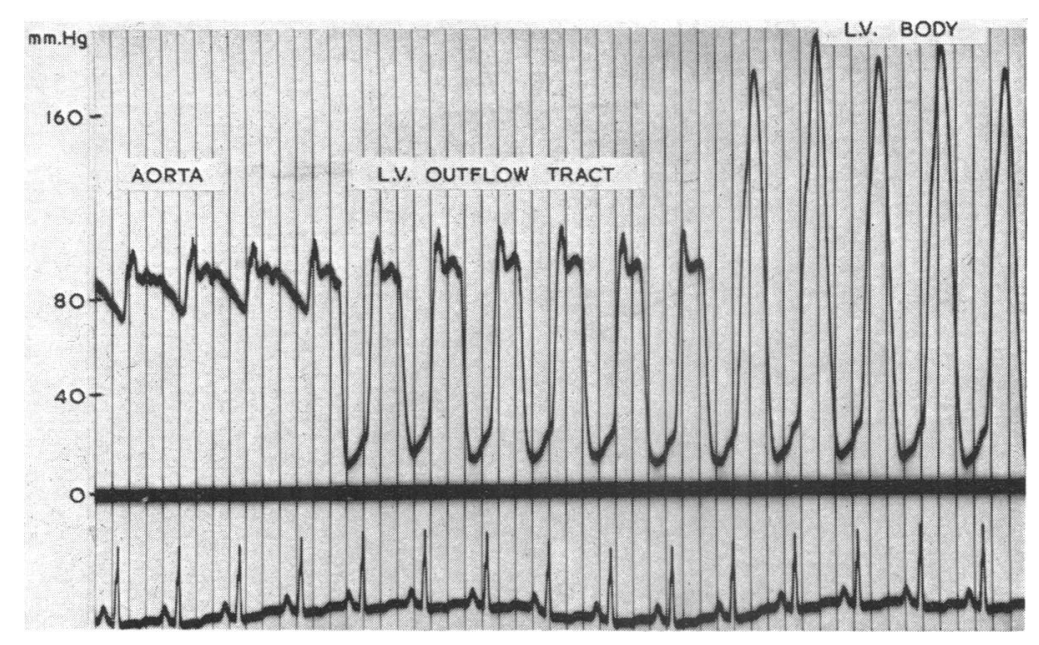

FIG. 9.-Withdrawal pressure trace across the left ventricular outflow tract in a case of surgically proven muscular subaortic stenosis (see text). The brachial arterial pressure trace in this case is shown in Fig. 1, and the simultaneous L.V. and B.A. trace in this case is the third tracing from the left in Fig. 7.

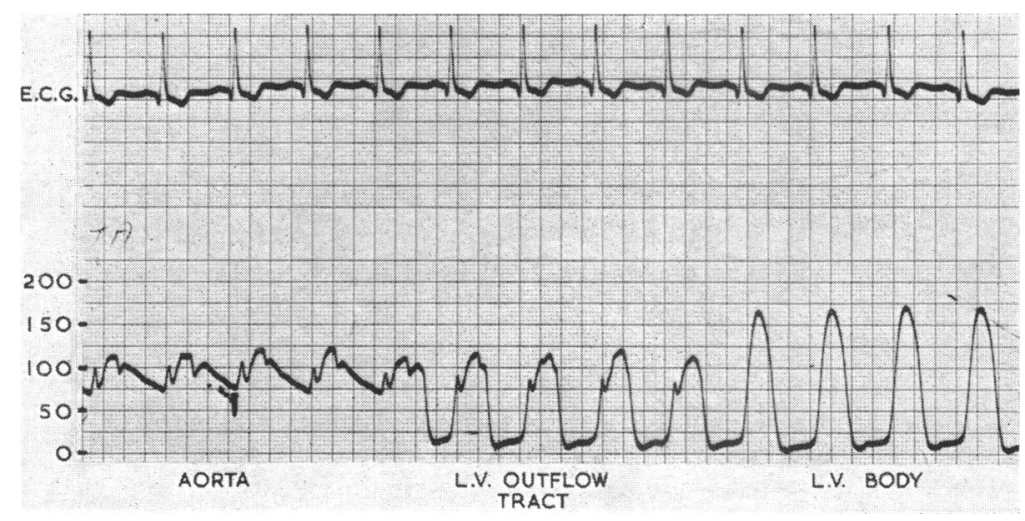

FIG. 10.-Withdrawal pressure trace across the left ventricular (L.V.) outflow tract in a case of discrete fixed subaortic stenosis. The simultaneous L.V. and B.A. traces from this case are shown in the lower half of Fig. 5 (see text).

and in muscular subaortic stenosis evidence of an infundibular chamber was once missed entirely. These inconsistencies in aortic and withdrawal pressure tracings lend increased importance to the analysis of peripheral arterial tracings in differentiating between muscular and discrete types of aortic stenosis.

In subvalvular aortic stenosis, a distinction should be made between the discrete, fixed, diaphragmatic type, the fibromuscular type, and the pure muscular type. Seven of the eight cases of discrete subaortic stenosis in this series were described at operation as being a diaphragm (6 cases) or fibrous bar (1 case): the eighth case was fibromuscular in type and, although no brachial arterial trace was available in this case, the rate of rise of pressure in the aortic tracing was slow and the upstroke time prolonged, and clinically, the pulse was described as small in volume. Hancock (1961) 
has reported that the shape of the brachial arterial pressure tracing in fibromuscular subaortic stenosis resembles that seen in muscular subaortic stenosis. The shape of the arterial pressure tracings in fibromuscular stenosis seems to depend on whether the fibrous (fixed) element or the muscular (contractile) element is dominant. In the one case of fibromuscular stenosis in this series, the fibrous element was described as the dominant obstructing factor.

The mechanism of the pulse differences between the muscular and discrete varieties of aortic stenosis has been discussed by Brachfeld and Gorlin (1959). In the muscular variety there is no obstruction in the early phase of the ejection of blood from the left ventricle allowing the formation of a normal percussion wave in the arterial pressure trace. With increasing contraction of the left ventricle, however, the hypertrophied muscle in the ventricular septum bulges into the outflow tract causing the pressure difference in late systole between the low left ventricle and the distal vascular channels. In the discrete varieties of left ventricular outflow tract obstruction, the obstruction to the ejection of blood from the left ventricle exists throughout systole: hence the rate of rise of pressure distal to the lesion is slow and the peak pressure (tidal wave) occurs late.

On palpating the brachial or radial arterial pulse it was possible to distinguish the sharp upstroke of the pulse in muscular subaortic stenosis from the slow rising, small volume pulse of valvular or discrete subvalvular aortic stenosis. This fact renders these pulse differences of clinical, as well as of hæmodynamic, value in differentiating muscular from discrete or fixed varieties of left ventricular outflow tract obstruction.

\section{Summary}

The brachial arterial pressure pulses have been analysed in 10 cases of muscular subaortic stenosis, 6 of 8 cases of discrete fixed subvalvular aortic stenosis, and 20 cases of valvular aortic stenosis, The distinguishing features in muscular subaortic stenosis were the rapid rise of pressure to an early 
peak systolic pressure (percussion wave), which resulted in a short systolic upstroke time to the peak systolic pressure. These characteristics contrasted with the findings in valvular and discrete fixed subvalvular aortic stenosis, where there was a slow rise in pressure to a low percussion wave (anacrotic notch) followed by a higher tidal wave (peak systolic pressure) which resulted in a prolonged systolic upstroke time to the peak systolic pressure.

The aortic pressure tracings in muscular subaortic stenosis were similar to the peripheral arterial tracing in all cases. In valvular and discrete subvalvular aortic stenosis most of the aortic tracing resembled the peripheral arterial tracing in each case, but when the catheter was near the obstruction, rapid rates of rise of pressure sometimes occurred, and these rendered differentiation from muscular subaortic stenosis less certain.

\section{ADDENDUM}

Since completion of this study a case has been investigated in which the brachial artery pressure tracing was characteristic of muscular subaortic stenosis yet the clinical findings in this case were those of aortic valvular stenosis. Operative confirmation of the diagnosis has been deferred, because the patient has a blood coagulation defect (Christmas disease). It is uncertain whether this case represents an exception to the observed pattern of brachial pulse in discrete valvular stenosis, i.e. slow rate of rise of pressure and a prolonged systolic upstroke time, or whether the brachial pulse truly reflects muscular subaortic stenosis, in this instance a functional muscular obstruction secondary to the valve stenosis. Hancock (1961) has described four cases of severe valvular aortic stenosis in which there was an "early-peaked arterial pulse." These four cases manifested secondary muscular obstruction following aortic valvotomy.

The author would like to express his gratitude to Dr. W. G. Bigelow, W. F. Greenwood, J. A. Key, R. O. Heimbecker, and R. W. Gunton for permission to study their cases, and to Mr. T. Nelberg for preparing the tracings for photography by the Department of Medical Photography, Toronto General Hospital.

\section{REFERENCES}

Bercu, B. A., Diettert, G. A., Danforth, W. H., Pund, E. E., Jr., Ahlvin, R. C., and Belliveau, R. R. (1958). Amer. J. Med., 25, 814.

Björk, V. O., Malmström, G., and Uggla, L. G. (1953). Ann. Surg., 138, 718.

Boiteau, G. M., and Allenstein, B. J. (1961). Amer. J. Cardiol., 8, 614.

Brachfeld, N., and Gorlin, R. (1959). Medicine (Baltimore), 38, 415.

Braunwald, E., Morrow, A. G., Cornell, W. P., Aygen, M. M., and Hilbish, T. F. (1960). Amer. J. Med., $29,924$.

Brent, L. B., Aburano, A., Fisher, D. L., Moran, T. J., Myers, J. D., and Taylor, W. J. (1960). Circulation, $21,167$.

Brock, R. (1957). Guy's Hosp. Rep., 106, 221. (1959). Guy's Hosp. Rep., 108, 126.

, and Fleming, P. R. (1956). Guy's Hosp. Rep., 105, 391.

Brockenbrough, E. C., Braunwald, E., and Morrow, A. G. (1961). Circulation, 23, 189.

Goodwin, J. F., Hollman, A., Cleland, W. P., and Teare, D. (1960). Brit. Heart J., 22, 403.

Hancock, E. W. (1961). Guy's Hosp. Rep., 110, 1.

Kjellberg, S. R., Mannheimer, E., Rudhe, U., and Jonsson, B. (1959). Diagnosis of Congenital Heart Disease, 2nd ed. Year Book Publishers, Chicago.

Morrow, A. G., and Braunwald, E. (1959). Circulation, 20, 181.

Paré, J. A. P., Fraser, R. G., Pirozynski, W. J., Shanks, J. A., and Stubington, D. (1961). Amer. J. Med., $31,37$.

Wigle, E. D., Heimbecker, R. O., and Gunton, R. W. (1962). Circulation, 26, 325.

Wood, P. (1958). Amer. J. Cardiol., 1, 553. 